\title{
Alternative method for minimally invasive determination of the wood fragility from cultural heritage assets
}

\author{
Constantin Ștefan Ionescu ${ }^{1, *}$, Aurel Lunguleasa ${ }^{1}$, Cosmin Spîrchez ${ }^{1}$, and Anamaria Avram² \\ ${ }^{1}$ Transilvania University of Brașov, Faculty of Wood Engineering, 500036 Bulevardul Eroilor 29, Brașov \\ ${ }^{2}$ Laboratory of Restoration and Research "Restaurare Ionescu Constantin", 550234 Henri Coandă 12, Sibiu
}

\begin{abstract}
The main objective of the paper is to present an alternative, original method, as a minimally invasive technical solution, to determine the hardness of the damaged wood from the cultural heritage objects. For comparison, standard hardness determinations, Brinell and Janka methods are considered. The correlation of conventional hardness test results with the Brinell method, compared to the proposed MARK 10 test shows that less equivocal methods can be used for equally sensitive values. The minimal invasive measurement solution offers advantages in use and is a novelty with applications for the polychrome wood restoration. In order to determine the destructive level of several methods that determine the hardness of the wood, the different areas of the imprint left by the penetrator are compared: Janka hardness $=100 \mathrm{~mm}^{2}$, Brinell hardness to maximum $78 \mathrm{~mm}^{2}$, Mark 10 puncture being only $1.41 \mathrm{~mm}^{2}$. The general conclusion of the paper highlights the strengths of the researched alternative, experimented and presented by us in order to determine the level of degradation of the wooden supports of the art objects of cultural patrimony. This method brings improvements for diagnosing the degradation level of wood panels as well as to evaluate the effectiveness of the consolidation treatment.
\end{abstract}

\section{Introduction}

The restoration of patrimony assets involves using techniques and materials in accordance with the state of degradation, the type of artifact, and especially, choosing the manner of subsequent exposure [1]. The need to investigate and scientifically determine the parameters that cause the deterioration of the wood support of art objects is due to the desire of saving that work of art. This is done by establishing a correct diagnosis and, based on that, coming up with a restoration project and quantifying the effectiveness of the treatment, with specific devices. An important element of the investigation is determining the level of lost physical, chemical and mechanical properties of the wood. It has suffered a severe biological attack (rot, xylophagic attack, etc.) which caused damage to the artistic creations which represent values of national or world cultural heritage [2]. Particular attention should be paid to the mechanical properties of the wood, which, due to the

\footnotetext{
* Corresponding author: restaurareionescu@gmail.com
} 
additional porosity produced by the xylophagic attack, loses its mass and the anatomical, mechanical strength. The excessive porosity of the wood, due to holes and insect galleries, leads to excessive moisture absorption which substantially changes the density and its mechanical properties. With increased humidity, the value of the flow limit decreases, and that raises the size of the deformities [3]. The mechanical properties of healthy wood, such as elasticity or hardness, depend on many factors such as anatomical features, apparent density, late wood percentage, natural porosity, etc [4-6]. Apparent density is interpreted by the mass to volume ratio where the volume varies with the bound water content and the mass based on the total water content [7].

Wood hardness is one of the properties that can assess the degree of fragility. Hardness is understood as the opposition of wood to the penetration of a body, expressed by resistance to mechanical action that tends to change its surface. There are several procedures to test the hardness of wood, but in the present paper we will refer to two conventional principles (commonly used), namely the Janka method and the Brinell method.

Janka hardness, according to ASTM D143-94,[8] is used as a minimally destructive test to estimate the strength and stiffness properties of wood. Currently, Janka hardness is a primary method used to assess the consistency of wood species for commercial and industrial use.[6] The Janka method (Figure 1.a) uses a ball with a diameter of 11,284 mm, which is pressed into wood on a depth equal to the radius, resulting in a $1 \mathrm{~cm}^{2}$ imprint. In this way, the force read on the universal machine dial is the real hardness of the wood, expressed in $\mathrm{daN} / \mathrm{cm}^{2}$ (this is explained by the fact that the hardness is usually expressed as the bulk of the resistance of the wood as the ratio between the force and the surface of the crushed section. The area of the tested section in our case is unitary) [3].

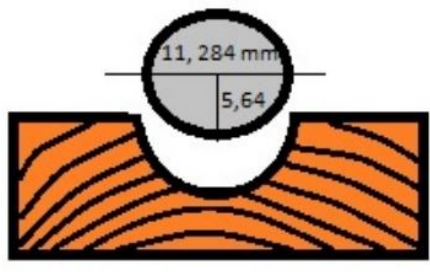

a. print type for Janka hardness

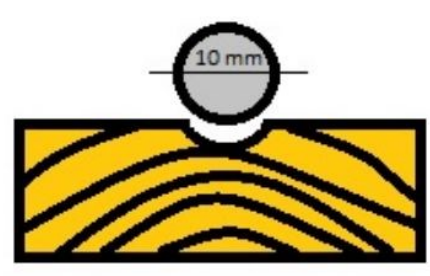

b. print type for Brinell hardness

Fig. 1. Graphic examples of standard hardness print types

Brinell Hardness testing (EN 1534-2000) [9] consists in using a $10 \mathrm{~mm}$ diameter steel ball (Figure 1.b.) which is pressed with a predetermined force of $100 \mathrm{daN}$; pressure is maintained for approximately $25 \pm 5$ seconds. The imprint has a certain diameter which is calculated as the arithmetic mean of two perpendicular diameters. After obtaining its value, the Brinell hardness with equation (1) is calculated, expressed in $\mathrm{N} / \mathrm{mm}^{2}$.

$$
H B=\frac{2 \cdot F}{\pi \cdot D\left(D-\sqrt{\left.D^{2}-d^{2}\right)}\right.}\left[\frac{N}{m m^{2}}\right]
$$

Where,

HB - Brinell hardness (Newton per square millimeter)

$\mathrm{F}$ - the pre-selectable push force in newtons

$\pi$ - is the ,pi" factor $\approx 3,14$

$\mathrm{D}$ - diameter of the ball $(10 \mathrm{~mm})$

$\mathrm{d}$ - diameter of the residual indentation 
The two methods of determining and assessing the hardness of the wood (healthy or damaged) are invasive and destructive, even if the mark is small (a diameter of about 4-8 $\mathrm{mm}$ in the case of Brinell hardness and $11.284 \mathrm{~mm}$ in the case of Janka hardness, and with a depth of 1-2.5 $\mathrm{mm}$ for Brinell and $5.64 \mathrm{~mm}$ for Janka). Although these traces are very small and testing can also be done on the back of the heritage object, we argue that the Janka and Brinell methods destroy some of the outer surface of the items, and this is undesirable. Moreover, these test methods are disadvantageous in that the stands are fixed and robust. They are suitable for testing small dimensional samples; the inconvenience of their use in restoration is the impossibility of extracting test specimens from the support of the cultural object. It should be noted that the polychrome panels vary in size and shape, and the distribution of the degradations is non-unitary.

Regarding the method of measuring hardness, Brinell or Janka, one cannot speak of novelty, yet our research brings an original contribution by having the alternative option of adapting and using a versatile device (Mark 10) and a method of calculating the force needed for a steel pin, $1.34 \mathrm{~mm}$ in diameter, to penetrate into a wooden panel. Comparing the compression or traction forces indicates the deterioration of the wood panels that have reached various degrees of degradation due to multiple reasons: aging of the material, loss of anatomical elements, physical and mechanical properties, or biological attack (fungi and xylophagic).

\section{Objective}

The main objective of the paper is: researching, developing and using an original alternative method to determine the hardness of damaged wood from art objects. This method presents lower destruction values, inferior to the two methods, Brinell and Janka. To solve this problem, the Mark 10 dynamometer is equipped with its own penetration tip and also with a device using fixing pins and a drive lever.

\section{Materials and methods}

The possibilities and the ways of measuring the wood hardness used in industry (construction, furniture, new wood, etc.) allow for measurements of samples that do not affect the final product, but, in the field of restoring works of art, measuring the hardness of degraded wood is quite limited, not being able to extract specimens that need to be subjected to different types of tests. It is desirable to obtain an alternative method for determining the hardness of an artifact whose wood support is damaged in order to determine its degree of fragility. Assessing this level of degradation caused by multiple causes (loss of mass or anatomical elements as a result of the action of xylophage insects, detachable fractures, etc.) leads to the friability of the wood. It is imperative to establish a restoration plan and finding out the stage of degradation, but also the effectiveness of the treatment. Clear scientific arguments are needed for this process.

The degree of wood fragility $\left(\mathrm{F}_{\mathrm{d}}\right)$ is determined by measuring the HM hardness, with Mark 10, as a percentage of the lost wood properties, compared to the initial value of healthy wood. In this respect, the authors formulated the calculation equation (2).

$$
F_{d}=\frac{H M_{S}-H M_{d}}{H M_{S}} \cdot 100[\%]
$$

Where: $F_{d}$ - is the degree of fragility in \%;

$\mathrm{HM}_{\mathrm{s}}$ - the healthy wood hardness determined with Mark 10 in N/mm² $\mathrm{HM}_{\mathrm{d}}$ - the hardness of the damaged wood determined by Mark 10, in N/mm²; 
The method of correlating the Brinell hardness measurement results with the wood resistance measurement done with the MARK 10 test bench, starts from the premise that puncture degradation is a less destructive method than the Janka and Brinell methods. We wanted to correlate the results obtained with one of the standardized procedures (the Brinell method, as an accepted option presented in this study), and to provide similar measurements, but with less damage than the benchmark. The imprint of this tip has a smaller diameter, or, at least, it is similar to the diameter of the flying holes produced by xylophage insects.

The Mark 10 test method is based on penetrating the wood with a cylindrical tip having a diameter of $1.34 \mathrm{~mm}$ and a length of $6 \mathrm{~mm}$ (Figure 2), using a force shown on the digital dynamometer's screen, expressed in [N]. This type of penetration is designed specifically for wood restoration applications and does not come with the device in commercial format.

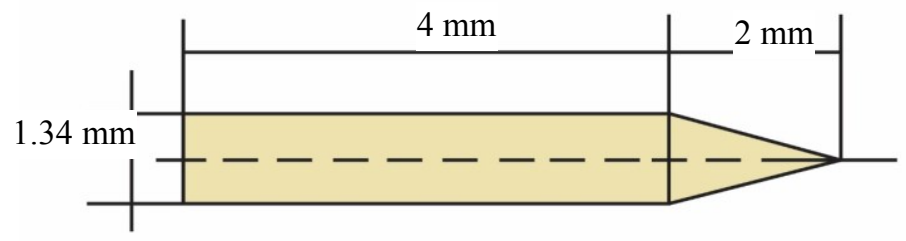

Fig. 2. The shape and size of the Mark 10 penetrator

Using the calculation formula designed by the authors, we determine the total lateral surface or the surface of the hole in the wood resulting from the penetration of the tip. The puncture resistance (hereafter referred to as "hardness Mark" (HM)) is calculated as the ratio of the punching force to the total lateral area of the cylinder and the cone, with relation (3).

$$
H M=\frac{2 \cdot F}{A_{l}}\left(\frac{N}{m m^{2}}\right)
$$

Where,

$\mathrm{HM}$ - hardness Mark in N/mm²

$\mathrm{F}$ - the force read on the Mark 10 dynamometer, in $\mathrm{N}$

$A_{1}$ - the total lateral surface of the peak penetrator, determined as a sum of the cylindrical and conical part $\left(21,28 \mathrm{~mm}^{2}\right)$.

The Mark 10 (M3-200) digital machine measures forces in Newtons, in a range of $0-1000 \mathrm{~N}$, and is designed to test compression and traction in many applications (including the wood panel of heritage items), using tips of different forms (Fig.3).

The device consists of: stand with columns, rack, centering and fixing plate, drive lever, dynamometer, penetrator (puncture tip).

The device has a software to help collect and process data through a computer, also to record and graphically transfer the time it takes the measuring tip to penetrate and the force needed to drive it in (Figure 4).

The material used for this study was healthy lime tree (Tilia cordata Mill.) and/or degraded. The samples (TD 4, 9, 10) had square sections of 20x20 mm and 50x50 mm, with variable lengths. These were subjected to the two types of testing, i.e. Brinell hardness and Mark 10 hardness (Figure 5). Measurements were made on three types of samples, degraded wood without treatment, new and healthy wood and wood with consolidation treatment, specific to the restoration field.

Separately, hardness determinations were performed only with the Mark 10 apparatus, on degraded panels of several icons in the restoration stages. For this study, I chose an example. The panel has the following dimensions: 730x630x24 mm. This is detailed in Example 1, the icon of St. Nicholas. 

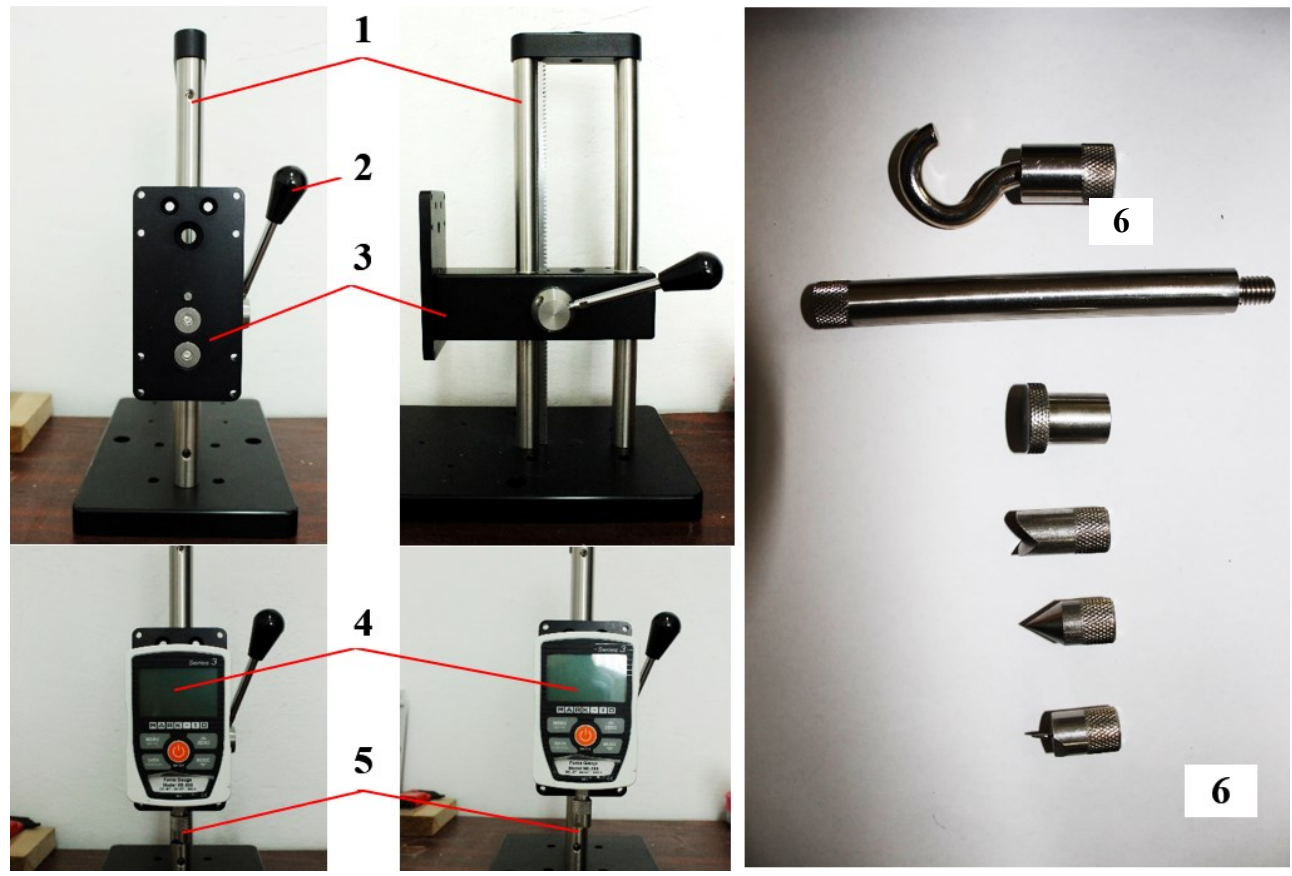

Fig. 3. Device with dynamometer Mark 10: 1 - dynamometer displacement columns; 2 - drive lever; 3 - dynamometer support plate; 4 - dynamometer; 5 - penetrator dial; 6 - current compression and traction peaks of the dynamometer

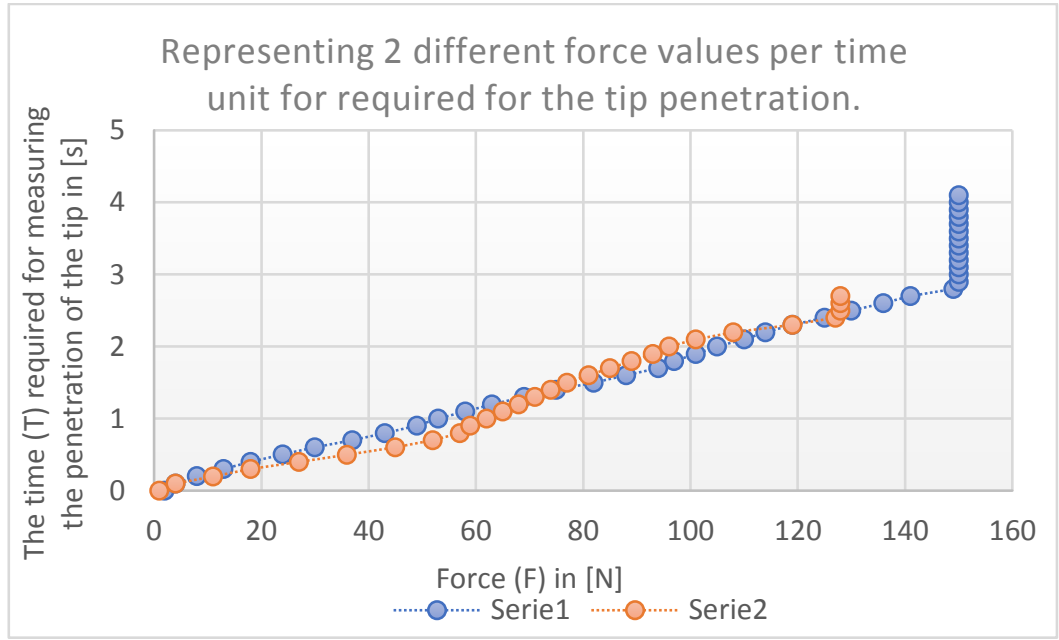

Fig. 4. Graphical determination of the push force and the time required for the tip to penetrate. Report of records with the Mark 10 

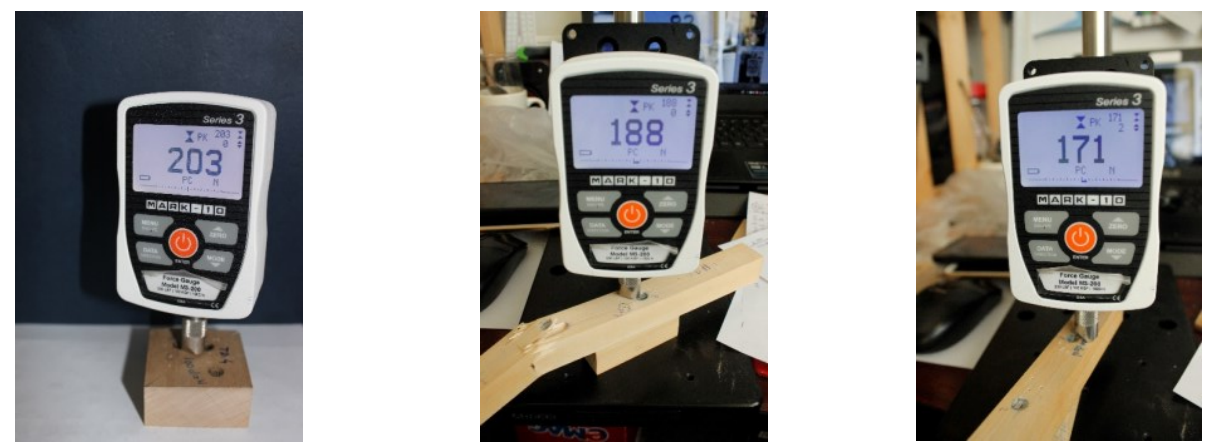

Fig. 5. Comparative determination of puncture force (HM) and Brinell hardness (HB) on new, healthy wood sample

\section{Results and discussions}

The obtained results are coming from a 24-month research with an investigation of 20 works of art and worship, and more than 350 wood specimens of various essences, at different stages of transformation, from healthy new wood to 370 years old wood with intense fungal and xylophagous attack, with values between 120-290 flight holes, which produce significant wood degradation [10-12].

These determinations are compared with the results of our previous research and the research done by others, using the available extensive bibliography. It produced results both in accordance with standard literature, as well as some additional results where the practice or literature did not produce ideas or technical solutions. That is why the high degree of novelty of our research contributes to:

- Creating and adapting a measuring device

- Elaborating the wood hardness measurement method (for the Mark 10 device) for works of art which have deteriorated over the course of history

- Determination of the hardness of the degraded wood leads to accurate diagnosis, the elaboration of a hierarchy of levels of deterioration on several steps of the old (historic) wood allows the determination of the degree of intervention in the restoration of the cultural object. At the same time, it offers the possibility to evaluate the efficiency of the consolidation treatment

- As far as we know, until this date, such a topic approach has not been published. This type of determination is not used in any other laboratory

- Our research makes it possible to establish a diagnosis for wood support based on hardness measurements and also provides the possibility of evaluating the efficiency of the consolidation treatment.

We consider the development of this research to be innovative, the authors contribution suggesting that the proposed method is completely original.

From these researches, the following examples are given for the present study, shown in detail in the following pages.

The results show that Mark (HM) hardness values are close to those of the Brinell hardness (HB) (Table 1), irrespective of the type of wood support (degraded or healthy).

Observing these results, a theory can be issued that the values obtained with the two types of measurements are close and can be taken into account independently of each other, especially if we refer to HM as a possibility measuring virtually some very fragile panels whose hardness values are only meant to compare the new wood to the wood that has reached a certain stage of degradation. 
Table 1. Mark and Brinell hardness, on the three types of samples, new wood, healthy degraded wood without treatment, and wood with consolidation treatment.

\begin{tabular}{|c|c|c|c|c|c|}
\hline \multirow[t]{2}{*}{ Specimens } & \multirow[t]{2}{*}{ No. } & \multirow{2}{*}{$\begin{array}{c}\mathrm{HB}, \\
\mathrm{N} / \mathbf{m m}^{2}\end{array}$} & \multirow{2}{*}{$\begin{array}{c}\text { HM, } \\
\mathrm{N} / \mathbf{m m}^{2}\end{array}$} & \multicolumn{2}{|c|}{ Fragility degree, \% } \\
\hline & & & & of $\mathrm{HB}$ & of $\mathrm{HM}$ \\
\hline \multirow{6}{*}{$\begin{array}{l}\text { TD4, New and } \\
\text { untreated wood }\end{array}$} & 1 & 18.36 & 19.07 & 0 (neutral) & 0 (neutral) \\
\hline & 2 & 17.35 & 17.95 & 0 (neutral) & 0 (neutral) \\
\hline & 3 & 15.11 & 13.43 & 0 (neutral) & 0 (neutral) \\
\hline & 4 & 17.45 & 17.00 & 0 (neutral) & 0 (neutral) \\
\hline & 5 & 16.95 & 16.62 & 0 (neutral) & 0 (neutral) \\
\hline & Medium & 17.20 & 16.81 & 0 (neutral) & 0 (neutral) \\
\hline \multirow{6}{*}{$\begin{array}{l}\text { TD9, Degraded } \\
\text { and untreated } \\
\text { wood }\end{array}$} & 1 & 4.14 & 2.91 & 77.4 & 84.7 \\
\hline & 2 & 4.56 & 3.85 & 73.7 & 78.5 \\
\hline & 3 & 5.30 & 7.51 & 64.9 & 44.0 \\
\hline & 4 & 4.46 & 4.85 & 74.4 & 71.4 \\
\hline & 5 & 4.76 & 4.65 & 71.9 & 72.0 \\
\hline & Medium & 4.66 & 4.75 & 72.9 & 71.7 \\
\hline \multirow{6}{*}{$\begin{array}{l}\text { TD10, Degraded } \\
\text { and treated wood }\end{array}$} & 1 & 11.52 & 10.53 & 37.2 & 44.7 \\
\hline & 2 & 7.72 & 5.35 & 55.5 & 70.1 \\
\hline & 3 & 9.75 & 8.74 & 35.4 & 34.9 \\
\hline & 4 & 9.86 & 8.35 & 43.4 & 50.8 \\
\hline & 5 & 9.46 & 8.05 & 52.5 & 51.5 \\
\hline & Medium & 9.66 & 8.20 & 43.8 & 51.2 \\
\hline
\end{tabular}

All these are aimed at issuing solutions, techniques, ways of approaching treatments and restoration interventions, to save the cultural good. If the HB hardness, obtained on standardized, recognized devices is important for resistance calculations, for example, then the solution adopted using this Mark 10 device in the field of restoration can bring minimal invasive clarifications and minimal acquisition efforts. Information similar to the standard one can be obtained, establishing, even in terms of hardness, a level of degradation produced on the panel of cultural goods.

When comparing the imprint of the three methods, it can be noticed that the Janka hardness, with a diameter of $11.284 \mathrm{~mm}$, produces a $100 \mathrm{~mm}^{2}$ mark, the Brinell method, with a ball of $10 \mathrm{~mm}$ produces a maximum of $78.5 \mathrm{~mm}^{2}$ and Mark 10, with a diameter of $1.34 \mathrm{~mm}$ leaves a trace of $1.41 \mathrm{~mm}^{2}$ (Figure 6).

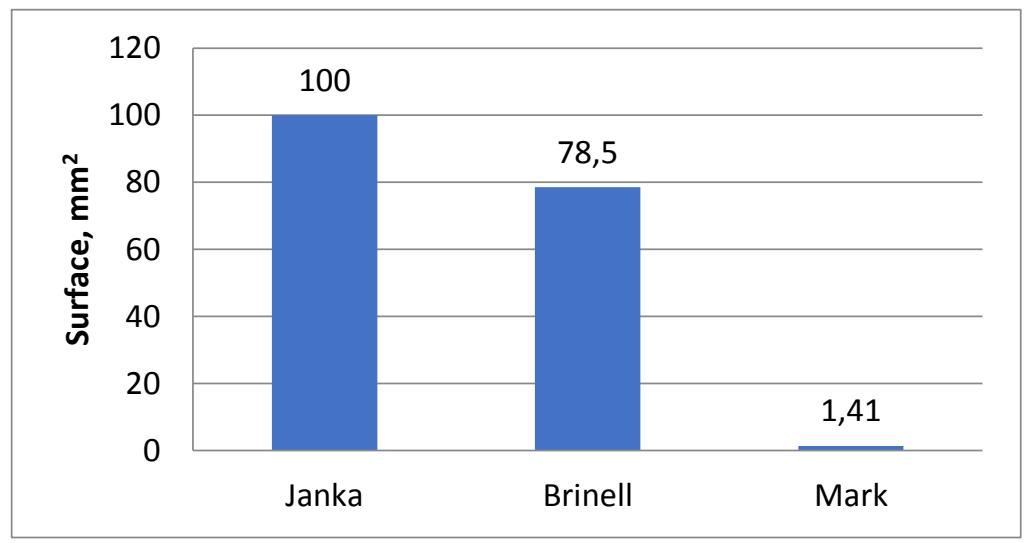

Fig. 6. Maximum imprint of Janka, Brinell and Mark hardness 
The fact that the smallest damage is caused by the Mark 10 apparatus, the remaining hole diameter is smaller than a xylophage insect flight hole (Fig.7). This process, using this device, and comparing it with a standardized method, is a novelty element at national and international level, with direct application to the degraded wood restoration of heritage objects.

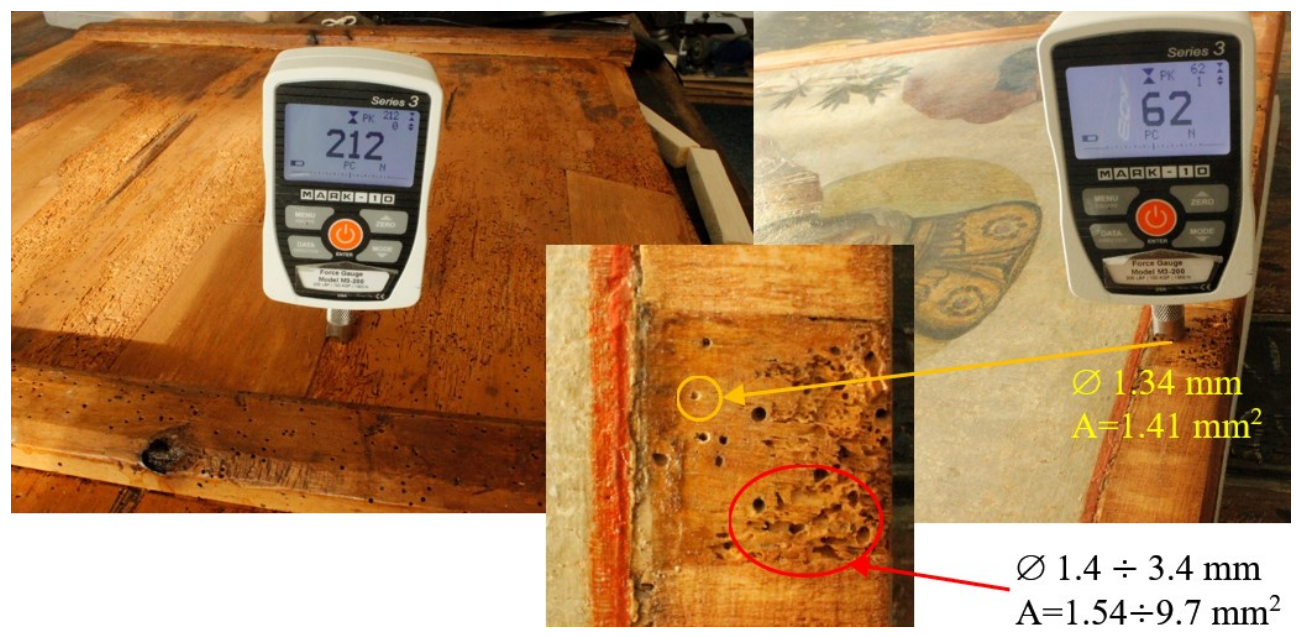

Fig. 7. Comparison of the tip of the measuring tip with the flight aperture caused by the xylophage insects: a) tip Mark 10, Ø 1,34 mm A=1,41 mm², b) flight holes, Ø 1.4- $3.4 \mathrm{~mm}, \mathrm{~A}=1.54-9.07 \mathrm{~mm}^{2}$. Values obtained after consolidation treatments showing improvement in hardness.

\section{Example 1 St. Nicholas Icon, dating back to the 19th century}

The icon had the following characteristics: species linden, dimensions 780x630x24 mm, humidity $9 \%$, density $435.40 \mathrm{~kg} / \mathrm{m}^{3}$ and excessive porosity caused by xylophagous attack, 142-170 holes $/ \mathrm{dm}^{2}$, values of pressure forces measured with Mark 10 expressed in N, were as follows:

a) Degraded zone: $5,12,13,24,29,44 ; 18 ; 23(\mathrm{~N})$ with an average value of $21 \mathrm{~N}$;

b) Medium degraded area: 33, 56, 84, 103, 132, 45; 60; $72(\mathrm{~N})$ with an average value of $73 \mathrm{~N}$.

For comparison, new lime, without defects, was used; measured with the Mark 10 dynamometer and the following values were obtained:

c) $179,191,211,216,219,210,198$ and $214(\mathrm{~N})$ with an average value of $204 \mathrm{~N}$. An $89.70 \%$ degree of fragility was determined for the seriously degraded area, $64.21 \%$ for the average degraded area and Equation 2 was used. The strength of the wood support varies significantly depending on the number of insect holes.

As the wood has variable deformations, the entire $\mathrm{HM}\left(\mathrm{N} / \mathrm{mm}^{2}\right)$ hardness values (Figure 8) have been differentiated (Table 2). The efficacy of the treatment was determined with the Equation 4).

Where,

$$
\mathrm{E}_{\mathrm{T}}=\frac{A 2-A 1}{A 1} \cdot 100[\%]
$$

$\mathrm{E}^{\mathrm{T}}=$ consolidation treatment efficiency

A1 = initial hardness, before treatment, in $\mathrm{N} / \mathrm{mm}^{2}$

$\mathrm{A} 2$ = hardness after consolidation treatment in $\mathrm{N} / \mathrm{mm}^{2}$

Although the treatment efficiency has high percentages and the hardness of the wood measured with Mark 10 (HM) offers improved values compared to the initial stage, the wood after treatment remains fragile with respect to new, healthy wood (e.g. 17.00-20.00 N/mm² according to Table 1). 


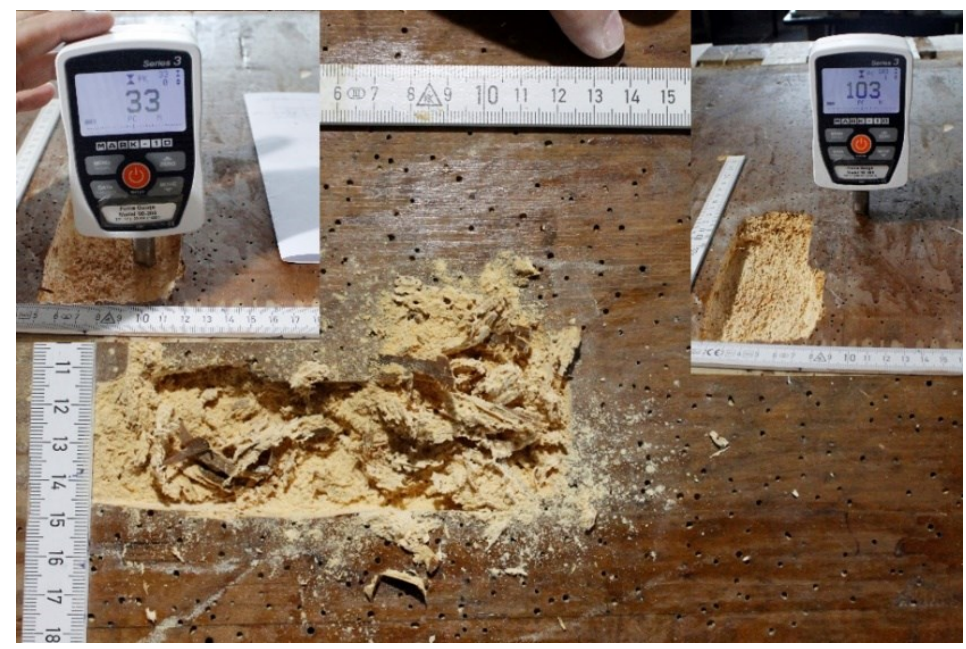

Fig. 8. Hardness determinations with Mark 10 before consolidation treatments

It can be seen that the effectiveness of the treatment is relevant, but the hardness determined later, shows that the maneuverability of the work must be carefully developed. The tests define the need to evaluate the treatment efficiency but also the level of hardness improvement, from the initial stage to a certain stage, and then, compared to the reference values of a healthy wood of the same species, by the measurement method proposed by we (HM) have the possibility to use the Mark 10 stand.

Table 2. HM hardness values before (A1) and after consolidation treatment (A2), expressed in $\mathrm{N} / \mathrm{mm}^{2}$ and efficiency

\begin{tabular}{|c|c|c|c|c|c|c|}
\hline \multirow[t]{2}{*}{$\begin{array}{c}\text { Type of } \\
\text { measurement }\end{array}$} & \multicolumn{2}{|c|}{$\begin{array}{c}\text { Before treatment } \\
{\left[\mathbf{N} / \mathbf{m m}^{2}\right]} \\
\text { A1 }\end{array}$} & \multicolumn{2}{|c|}{$\begin{array}{c}\text { After treatment } \\
{\left[\mathbf{N} / \mathbf{m m}^{2}\right]} \\
\text { A2 }\end{array}$} & \multicolumn{2}{|c|}{$\begin{array}{c}\text { Efficiency } \\
\% \\
\text { (Eq. 4) } \\
\end{array}$} \\
\hline & $\begin{array}{c}\text { Very } \\
\text { damaged } \\
\text { wood } \\
\end{array}$ & $\begin{array}{c}\text { Medium } \\
\text { damaged } \\
\text { wood } \\
\end{array}$ & $\begin{array}{c}\text { Very } \\
\text { damaged } \\
\text { wood } \\
\end{array}$ & $\begin{array}{c}\text { Medium } \\
\text { damaged } \\
\text { wood } \\
\end{array}$ & $\begin{array}{c}\text { Very } \\
\text { damaged } \\
\text { wood } \\
\end{array}$ & $\begin{array}{c}\text { Medium } \\
\text { damaged } \\
\text { wood }\end{array}$ \\
\hline Compression PC & 0.47 & 6.10 & 1.12 & 7.33 & 138.29 & 20.16 \\
\hline Traction & 0.19 & 1.59 & 0.65 & 1.97 & 242.10 & 23.89 \\
\hline Compression PC & 1.03 & 7.89 & 2.16 & 9.40 & 109.70 & 19.13 \\
\hline Traction & 0.37 & 1.59 & 0.84 & 2.91 & 127.02 & 83.01 \\
\hline Compression PC & 2.16 & 9.30 & 3.10 & 12.40 & 43.51 & 33.33 \\
\hline Traction & 0.47 & 3.47 & 0.75 & 3.85 & 59.57 & 10.95 \\
\hline Compression PC & 4.13 & 9.68 & 5.07 & 12.97 & 22.76 & 33.98 \\
\hline Traction & 1.22 & 1.78 & 1.97 & 2.53 & 61.47 & 42.13 \\
\hline Compression PC & 5.26 & 12.40 & 7.14 & 19.92 & 35.74 & 60.64 \\
\hline Traction $\quad$ PT & 1.03 & 5.45 & 1.78 & 6.67 & 72.81 & 22.38 \\
\hline
\end{tabular}

\section{CONCLUSIONS}

From the experiments performed in the paper, there were clear advantages in favor of using the Mark hardness, compared to the hardness of Brinell and Janka. A first advantage is that the type of measurement is minimally invasive; the hole left by the penetrating tip has a diameter of $1.34 \mathrm{~mm}$, compared to the diameter of the Brinell imprint (3-9 $\mathrm{mm})$. 
The mobility of the Mark 10 is superior in size and portability.

The ability to record and store measured values in real-time electronic format is another advantage of this type of device. Last but not least, the low cost of use compared to the Brinell stand is highlighted.

Mark 10 Hardness Measurement (HM) is an advantage to the polychrome wood restoration industry from the point of view of the investigations, providing a diagnosis as well as a response to the consolidation treatment performed, determining its effectiveness.

\section{References}

1. C. S. Ionescu, Drobeta, XXIV, 161-177 (2016)

2. A. Bedate, L. C. Herrero, J. A. Sanz, J. Cult. Herit. 5, 101-111 (2004)

3. I. Curtu, N. Ghelmeziu, Mecanica lemnului şi a materialelor pe bază de lemn, Ed. Tehnică, București (1984)

4. P. Pescăruș, M. Cismaru, Studiul lemnului. Îndrumar pentru lucrări practice, Universitatea din Braşov (1979)

5. P. Pescăruș, Studiul lemnului. Îndrumar de lucrări practice, Universitatea din Brașov (1983)

6. M. C. Wiemann, W. D. Green, Estimating Janka Hardness from Specific Gravity for Tropical and Temperate Species

https://www.fpl.fs.fed.us/documnts/fplrp/fpl_rp643.pdf. accessed January 2019

7. P. Pescăruș, Tehnologia prelucrării lemnului, 1, 64-89 (1978)

8. ASTM D143 - 94 - Standard Test Methods for Small Clear Specimens of Timber https://www.astm.org/ DATABASE.CART/HISTORICAL/D143-94.htm. Accessed January 2019

9. European Standard (EN 1534-2000), Wood and parquet flooring - Determination of resistance to indentation (Brinell) - Test method, March 2000

10. L. Bucșa, L. Bucșa, Degradări biologice ale structurilor de lemn la monumentele istorice din Romania, bucsa degr biologice str lemn.pdf, (accessed May 2017)

11. D. K. Kurzeluk, Studiul bioecologiei coleopterului xilofag anobium punctatum DeGeer, 1774, dăunător per obiectele de patrimoniu din lemn, https://www.researchgate.net/publication/321033584, (accessed August 2018)

12. C. S. Ionescu, Drobeta, XXIV, 95-117 (2014)

13. The wood database (2019): Wood Identification guide, https://www.wood-database.com/woodarticles/wood-identification-guide/, (accessed January 2019) 